\title{
Detection of genetic variation in Ustilago maydis strains by probes derived from telomeric sequences
}

\author{
Patricia Sánchez-Alonso, ${ }^{1}$ María Elena Valverde, ${ }^{2}$ Octavio Paredes-López ${ }^{2}$ \\ and Plinio Guzmán ${ }^{1}$
}

\begin{abstract}
Author for correspondence: Plinio Guzmán. Tel: +5246251600 ext. 447. Fax: +52 46251282.
e-mail: pguzman@irapuato.ira.cinvestav.mx
\end{abstract}

Departamento de

Ingeniería Genética de

Plantas ${ }^{1}$ and

Departamento de

Biotecnología y

Bioquímica², Centro de

Investigación y de Estudios

Avanzados del IPN, Unidad

Irapuato, Apartado Postal

629, 36500, Irapuato, GTO,

Mexico

\begin{abstract}
Genetic variation using probes derived from telomeric sequences was analysed among several Ustilago maydis strains in an attempt to identify discriminative fingerprint patterns. Three groups of wild isolates from different geographical areas and one group of standard laboratory strains were examined. Analysis of the endmost restriction fragments (EFs) and of the endmost-associated restriction fragments (EAFs) of the chromosomes revealed group differences. Most of the EFs in two groups of strains showed a similar length whereas in the other two groups they were distributed in classes of different lengths. Furthermore, analysis of the EAFs permitted possible fingerprint patterns to be predicted for each group of strains based on the occurrence of amplified bands as well as the presence or absence of distinct bands which were shown to be present in terminal as well as in interstitial sites of the chromosome. The approach evaluated in this work yielded highly polymorphic fingerprint patterns and could be used to distinguish groups of fungal isolates; this approach may also be effective for other fungal systems.
\end{abstract}

Keywords: Ustilago maydis, telomeres, fingerprint analysis

\section{INTRODUCTION}

The chromosome termini in eukaryotes are often rich in repeated DNA sequences (Zakian, 1989). Short sequences which are tandemly repeated, or large repeated sequences of the non-long terminal repeat retroposon type are present at the chromosome end (Blackburn, 1994). The short DNA sequences are most commonly found and they are highly conserved among eukaryotes, whereas the nonlong terminal repeat retroposon type have only been described in Drosophila (Levis et al., 1993). Repeated DNA sequences are also present adjacent to the chromosome end. These sequences, known as telomere-associated sequences (TAS), are not as conserved as the telomeric repeat and in most cases they are polymorphic on the genome and harbour a mixture of repetitive elements (Foote \& Kemp, 1989; Brown et al., 1990; Louis et al., 1994; Farman \& Leong, 1995).

Abbreviations: TAS, telomere-associated sequences; TR, telomeric repeat; TR-p, TR-proximal; TR-d, TR-distal; EF, endmost restriction fragment; $E A F$, endmost-associated restriction fragment.
We are interested in the organization of the Ustilago maydis genome. U. maydis is a basidiomycetous fungus that causes smut disease in maize (Banuett, 1992; Spellig et al., 1994; Valverde et al., 1995) and is an organism for which molecular genetic analysis has been well developed (Wang et al., 1988; Fotheringham \& Holloman, 1989; Gold et al., 1994; Bölker et al., 1995; Kamper et al., 1995). We have previously characterized telomeric regions from this fungus (Guzmán \& Sánchez, 1994); they show the sequence T'TAGGG, tandemly repeated at least 37 times at the chromosome termini, which is identical to the telomere repeats found in humans and other vertebrates as well as in some protozoa and moulds. Analysis of the TAS has revealed that the same segment was adjacent to the telomeric repeat in many or all of the chromosomes (Guzmán \& Sánchez, 1994). In this study we have devised a new approach to analyse genetic variability in $U$. maydis. Fingerprints of $U$. maydis isolates collected from three different geographical areas and of two standard laboratory strains were obtained using probes from the telomeric and telomeric-associated regions of the chromosomes. This analysis permitted the identification of distinctive fingerprint patterns for each group of strains. 


\section{METHODS}

U. maydis isolates. Strains used in this study are listed in Table 1. Teliospores were collected from smut galls of naturally infected maize (Valverde, 1992). Spore masses were lyophilized, stored at $4{ }^{\circ} \mathrm{C}$ and sporidia were isolated as previously described (Thakur et al., 1989; Pope \& McCarter, 1992). Teliospores were germinated on potato dextrose agar (PDA, Difco) at $28^{\circ} \mathrm{C}$. Single haploid progenies were obtained by plating on PDA.

DNA isolation and Ba/31 digestion. U. maydis DNA was prepared as follows. Sporidia were grown in $250 \mathrm{ml}$ potato dextrose broth (PDB) in a 1 litre Erlenmeyer flask agitated in a reciprocal shaker (200 r.p.m.) for $24 \mathrm{~h}$ at $28^{\circ} \mathrm{C}$. Cells were collected by centrifugation and washed twice in a solution containing $100 \mathrm{mM}$ Tris $/ \mathrm{HCl}, \mathrm{pH} 8.0,5 \mathrm{mM}$ EDTA and $150 \mathrm{mM} \mathrm{NaCl}$. After freeze-drying, cells were frozen in liquid nitrogen, ground to a powder and lysed in a solution containing $200 \mathrm{mM}$ Tris/ $\mathrm{HCl}, \mathrm{pH} 8 \cdot 0,100 \mathrm{mM}$ EDTA, $1 \%$ Sarkosyl and $1 \mathrm{mg}$ Proteinase $\mathrm{K} \mathrm{ml}^{-1}$ for $1 \mathrm{~h}$ at $50^{\circ} \mathrm{C}$. The DNA was purified by several phenol/chloroform extractions, ethanol-precipitated and resuspended in TE $(10 \mathrm{mM}$ Tris $/ \mathrm{HCl}, \mathrm{pH} 8 \cdot 0,1 \mathrm{mM}$ EDTA). Bal31 digestion of genomic DNA was performed as previously described (Guzmán \& Sánchez, 1994).

Southern hybridization. DNA samples were digested to completion with Pst $\mathrm{I}$ (Gibco-BRL). DNAs were size-fractionated by agarose gel electrophoresis on a $0.8 \%$ gel and transferred to a nylon membrane (Hybond-N, Amersham) as described by Sambrook et al. (1989). Hybridizations were carried out at $65^{\circ} \mathrm{C}$

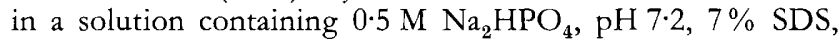
$1 \mathrm{mM}$ EDTA and $1 \%(\mathrm{w} / \mathrm{v})$ BSA at a probe concentration of $10^{6}$ c.p.m. $\mathrm{ml}^{-1}$ (Church \& Gilbert, 1984). Membranes were washed with a solution containing $0.2 \times \mathrm{SSPE} / 0.1 \%$ SDS at $65^{\circ} \mathrm{C}$. For removal of probes the following treatment was repeated at least twice: a solution of $0.1 \% \mathrm{SDS} / 0 \cdot 1 \times \mathrm{SSPE}$ was boiled and poured on the membrane and allowed to cool to room temperature $(1 \times \mathrm{SSPE}$ is $0.15 \mathrm{M} \mathrm{NaCl}, 0.01 \mathrm{M}$ sodium phosphate, $1 \mathrm{mM}$ EDTA).

Source of probes. DNA segments containing telomeric DNA from $U$. maydis were used as probes. Three segments from the telomeric region were obtained after digestion with $P_{s t} \mathrm{I}$ and HincII and from enzymes recognizing restriction sequences at the polylinker of the vector $\mathrm{pBSKS}^{-}\left(K p n \mathrm{I}\right.$ and $S_{a c} \mathrm{I}$, Stratagene); three clones in the $\mathrm{pBSKS}^{-}$vector were generated which encompassed most of the region. The restriction sites and the location of the probes within the telomeric region are shown in
Fig. 1. DNA fragments used as probes were eluted from the gel using the Bio-Rad Prep-A-Gene DNA purification kit or by a freeze-squeeze procedure (Silhavy et al., 1984). Purified DNA was then labelled using a Random Primer kit from Amersham; probes at a concentration of $5 \times 10^{5}$ c.p.m ml $\mathrm{m}^{-1}$ were usually generated.

\section{RESULTS AND DISCUSSION}

\section{Detection of genetic variation in $U$. maydis strains}

In previous work, a segment of middle-repeated sequences adjacent to the telomeric repeat was inferred to be very similar in sequence in many if not all of the $U$. maydis chromosomes (Guzmán \& Sánchez, 1994); this segment included a recognition site for the endonuclease Pst I near the chromosome terminus. Based on this information and considering that the telomeric regions of the chromosomes are rich in repeated DNA sequences, we decided to explore the possibility of using these sequences to detect genetic variation among fungal isolates. We assumed that PstI would dissect the chromosome ends, generating an

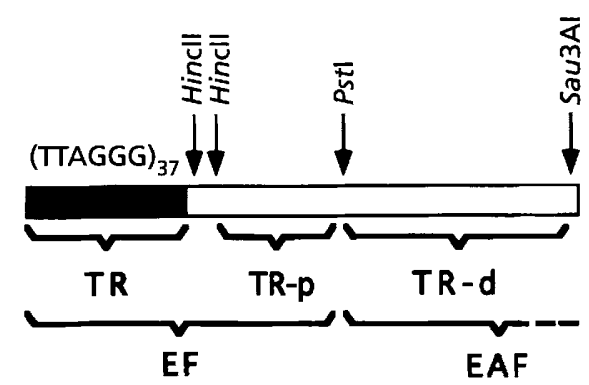

Fig. 1. Schematic illustration of the telomeric region from $U$. maydis. DNA fragments used as probes: TR, a Hincll-Kpnl segment containing 37 copies of the TR sequence TTAGGG shown in black (Kpnl is a site in the vector); TR-p, a $83 \mathrm{bp}$ Sau3Al-Hincll fragment adjacent to the TR; and TR-d, a $84 \mathrm{bp}$ Sau3Al-Pstl fragment of the TAS. The predicted restriction fragments generated after a Pstl digest are indicated as EF and EAF; the illustration is not to scale.

Table 1. U. maydis strains

\begin{tabular}{|lcc|}
\hline Strain & \multicolumn{1}{c|}{ Origin } & Reference/source \\
\hline Group 1 & & \\
FB1a1b1, FB2a2b2 & Obtained from the same teliospore; & Banuett \& Herskowitz (1989) \\
standard laboratory strains & \\
Group 2 & Wild isolates, collected in Irapuato, I3, I4 & Valverde (1992) \\
Group 3 & GTO, Mexico & \\
P1, P2 & Wild isolates, collected in Pachuca, & Valverde (1992) \\
Group 4 & HGO, Mexico & \\
T1, T2, T3, T4, T5 & Wild isolates, collected in Toluca, & Valverde (1992) \\
& MEX, Mexico & \\
\hline
\end{tabular}


(a)

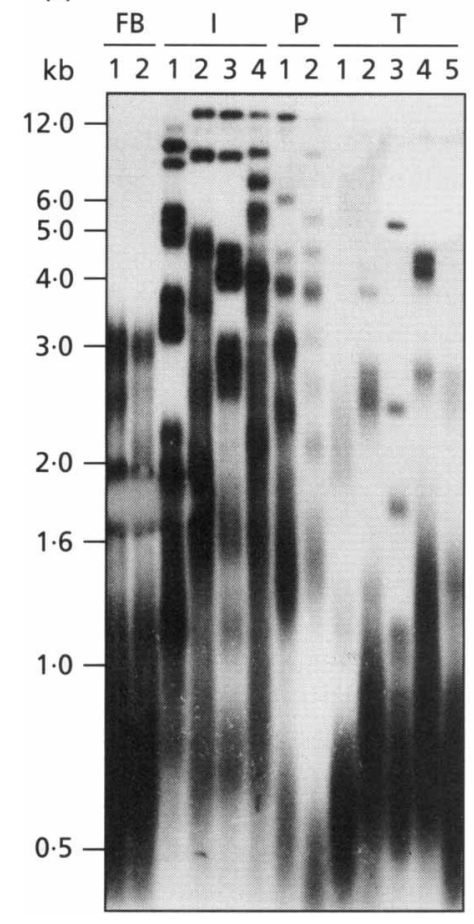

(b)

kb $\frac{\mathrm{FB}}{12} \frac{\mathrm{l}}{1234} \frac{\mathrm{P}}{12} \frac{\mathrm{T}}{12345}$

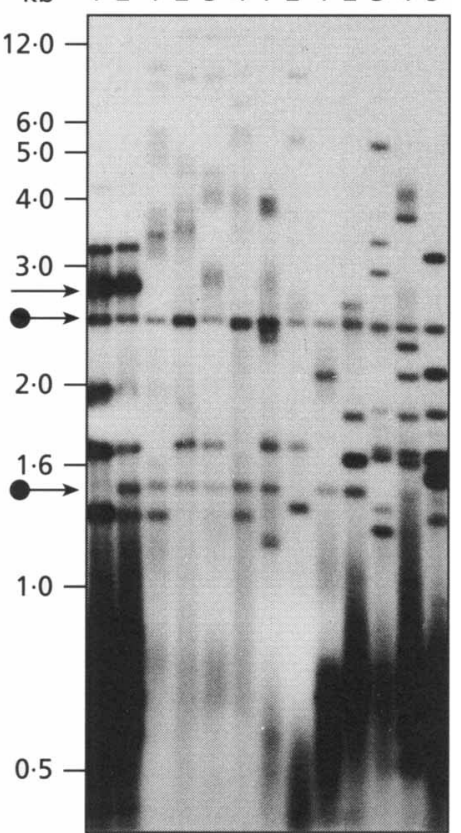

Fig. 2. Fingerprint analysis with probes encompassing the $\mathrm{EF}$ of $U$. maydis chromosomes. DNA was isolated from the four groups of $U$. maydis strains listed in Table 1 (strains in groups 1-4 are prefixed FB, I, P and T, respectively). Samples $(0.5 \mu \mathrm{g})$ of the DNAs were digested to completion with Pstl, size-fractionated by agarose gel electrophoresis $\left(0.8 \% \mathrm{gel}_{1} 1.2 \mathrm{~V} \mathrm{~cm}^{-1}\right.$ for $26 \mathrm{~h}$ ) and transferred to a nylon membrane. The blot was hybridized under highstringency conditions with TR (a) or with TRp (b) (see Fig 1). Hybridization was first performed with TR-p, followed by removal of the probe and hybridization with TR. The arrow points to a $2.9 \mathrm{~kb}$ band present in group 1 ; arrows with a circle point to a $2.6 \mathrm{~kb}$ band common to all of the strains and a $1.5 \mathrm{~kb}$ band present in some of the strains. Size standards: Gibco BRL 1 kb DNA ladder. endmost restriction fragment (EF) that would include telomeric repeats (TRs), and an endmost-associated restriction fragment (EAF). This is schematically represented in Fig. 1. We reasoned that comparison of the hybridization pattern of $P_{s t} \mathrm{I}$ digests of genomic DNA using probes from $\mathrm{EF}$ or $\mathrm{EAF}$ might reveal variation among different isolates. Two probes from EF were used; one contained TRs and the other TR-proximal sequences (TR and TR-p, Fig. 1). Since the middle-repeated sequences adjacent to the TR were also predicted to be present in non-telomeric regions of the $U$. maydis genome (Guzmán \& Sánchez, 1994), comparison of the hybridization pattern generated by these two probes would be useful to distinguish hybridization bands derived from telomeric regions from those of non-telomeric regions of the chromosome; DNA fragments recognized by both probes would suggest a telomeric location.

\section{Analysis of variation with probes encompassing the EF of the chromosomes}

In an attempt to detect variation in EFs, we used the probes TR and TR-p, which encompass this region (Fig. 1). Southern blot analysis performed on $13 U$. maydis strains using TR detected mostly smears as hybridization signals (Fig. 2a), a pattern that is expected for hybridization with telomeric probes (Richards \& Ausubel, 1988). In the standard laboratory strains (group 1) and in one group of wild isolates (group 4) the bulk of hybridization signal was observed between 0.5 and $1 \mathrm{~kb}$ (Fig. 2a), indicating that the majority of the EFs lay in this size range (Table 2, column 2); in these two groups the predicted length of the EF is very similar. These results are in agreement with a previous observation of the length of $U$. maydis telomeres determined by Sau3AI digests (Guzmán \& Sánchez, 1994). Hybridization with $T R-p$ revealed a similar distribution as with $T R$, implying that both probes are detecting EFs.

Groups 2 and 3 showed a different fingerprint pattern from the previous groups of strains. A single major smear was not detected with the TR probe (Table 2, column 2); instead the smear was distributed in various regions in a broad range of sizes and distinct bands in the high molecular mass range of the gel were observed (Fig. 2a; lanes 3-8). These high molecular mass bands were also detected with TR-p, indicating that both probes were identifying EF sequences. The hybridization signals of the putative telomeric fragments were less intense with TR-p (Fig. 2b, lanes 3-8, from 3 to $12 \mathrm{~kb}$ ) than with TR (Fig. 2a; lanes 3-8); this observation, and the fact that differences in the size of the EF occurred, suggests that the TR-p sequences are not as homologous in groups 2 and 3 as they are in groups 1 and 4 .

The TR-p probe also revealed polymorphic fingerprints of distinct bands which were not detected when the blot was hybridized with TR (Table 2, column 3). Most of these bands, which were smaller than $3 \mathrm{~kb}$ in length, may correspond to TR-p-related sequences present in nontelomeric regions of the chromosome. Interestingly, group 1 displayed a band which was unique to this group of strains (Table 2, column 4). Other sets of bands, as shown in Fig. 2(b), were shared by several strains in a non-clonal distribution and with different intensities, for example the $1.5 \mathrm{~kb}$ band present in all isolates from groups 1 and 2 and in isolates P1, T1 and T2, and the bands common to all of the strains, such as the $2.6 \mathrm{~kb}$ band. 
Table 2. Summary of fingerprint differences

\begin{tabular}{|c|c|c|c|c|c|c|}
\hline \multirow[t]{2}{*}{ Group } & \multicolumn{3}{|c|}{ EFs } & \multicolumn{3}{|c|}{ EAFs $\ddagger$} \\
\hline & $\begin{array}{l}\text { No. of major smears } \\
(\text { probe TR })^{*}\end{array}$ & $\begin{array}{l}\text { No. of non- } \\
\text { telomeric bands } \\
\text { (probe TR-p) } \dagger\end{array}$ & $\begin{array}{c}\text { Bands unique to } \\
\text { group } \\
\text { (probe TR-p) } \dagger\end{array}$ & No. of bands & $\begin{array}{c}\text { Presence of } \\
\text { amplified bands } \\
<1 \mathrm{~kb}\end{array}$ & $\begin{array}{c}\text { Bands unique to } \\
\text { group }\end{array}$ \\
\hline 1 & $1(\sim 0.95 \mathrm{~kb}) \Subset$ & $8-10$ & $1(\sim 2.9 \mathrm{~kb})$ & $14-15$ & + & $1(\sim 1 \mathrm{~kb})$ \\
\hline 2 & 3-5 & 3 & - & $13-18$ & - & - \\
\hline 3 & 4-6 & $3-5$ & - & $17-20$ & - & $1(\sim 0.61 \mathrm{~kb})$ \\
\hline 4 & $1(\sim 0.83 \mathrm{~kb}) \mathbb{\S}$ & $4-10$ & - & $20-26$ & + & $1(\sim 0.71 \mathrm{~kb})$ \\
\hline
\end{tabular}

* Data from Fig. 2(a). †Data from Fig. 2(b). $\quad \ddagger$ Data from Fig. 3.

$₫$ Mean of EF lengths, determined according to Harley et al. (1990).

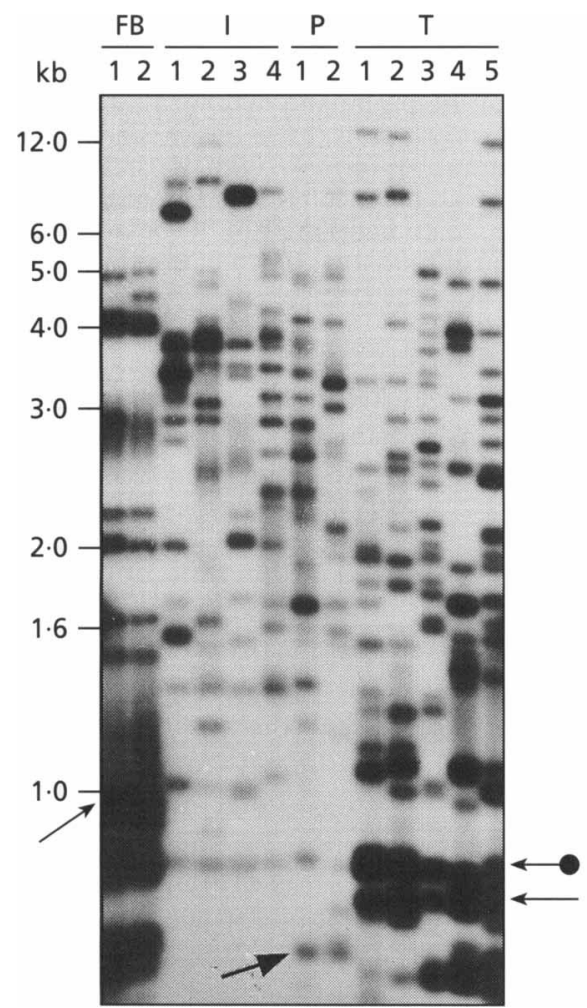

Fig. 3. Fingerprint analysis with probes encompassing the EAFs of $U$. maydis chromosomes. The blot described in Fig. 2 was hybridized with the TR-d probe (Fig. 1). Before hybridization, the removal of the previous probe was verified by exposure of the membrane to X-ray film. Arrows point to a $1.0 \mathrm{~kb}$ band present in group 1, a $0.61 \mathrm{~kb}$ band in group 3 and a $0.71 \mathrm{~kb}$ band in group 4 ; the arrow with a circle points a $0.79 \mathrm{~kb}$ band common to all of the strains which may be amplified in groups 1 and 4 . Size standards as in fig. 2.

\section{Analysis of variation with a probe encompassing the EAF of the chromosomes}

Variation in the EAF was assessed by using the TR-distal fragment flanking the Pst I site toward the centromere as a probe (Fig. 1). Since the middle-repeated sequences adjacent to the TR were probably also present in non- telomeric regions of the genome (Guzmán \& Sánchez, 1994), a complex fingerprint pattern was expected to be obtained. Most of the hybridizing signals detected in all of the strains by the TR-d probe were distinct bands and not smears, demonstrating that this probe was not hybridizing to EFs (Fig. 3). Interestingly, all the strains showed a broad range of hybridizing bands, indicating that their genomes contained sequences homologous to TR-d.

The number of bands hybridizing to TR-d was higher than that detected with TR-p, with group 4 displaying the highest number of hybridizing bands (Table 2, compare columns 3 and 5). Comparison of the hybridizing signals revealed possible single differences for all of the groups. Strains in groups 1 and 4 showed amplified signals in the low molecular mass region that were not present in the other two groups (Table 2, column 6). One such signal in group 1 and another in group 4 may be distinctive for each of these two groups (Table 2, column 7). Strains from groups 2 and 3 displayed similar fingerprint patterns; for example, I4 and P1 were very similar (Fig. 3, lanes 6 and 7), but they could still be differentiated. These two groups of strains could be distinguished by the presence of a $0.61 \mathrm{~kb}$ band in the two isolates from group 3 that was not present in any of the isolates from group 2 (Fig. 3, lanes $3-8)$. This band may be characteristic of group 3 (Table 2, column 7); if it is detected in groups 1 and 4 it could appear but among the amplified bands. The rest of the bands from the blot shown in Fig. 3 were seemingly random and could not be associated with the origin of the strains.

\section{Polymorphisms occur at terminal and interstitial regions of the chromosome}

The three probes of telomeric origin revealed highly polymorphic fingerprint patterns in $U$. maydis strains. The DNA sequences detected by these probes are thought to be mainly telomeric but they may also include interstitial regions of the chromosomes (Guzmán \& Sánchez, 1994). In an attempt to distinguish between telomeric and interstitial polymorphisms, sensitivity of telomeric sequences to exonuclease treatment was used. In this way, the proportion of TR-and TR-d-related DNA sequences 
(a)

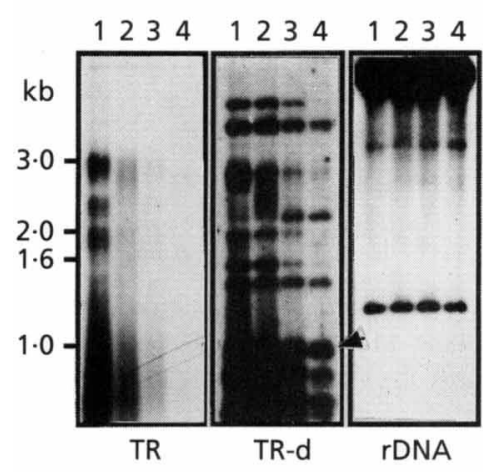

(b)

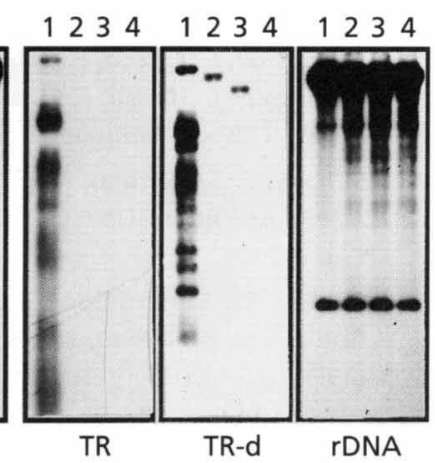

(c)

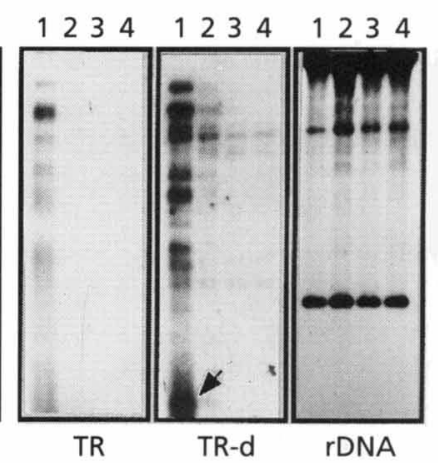

(d)

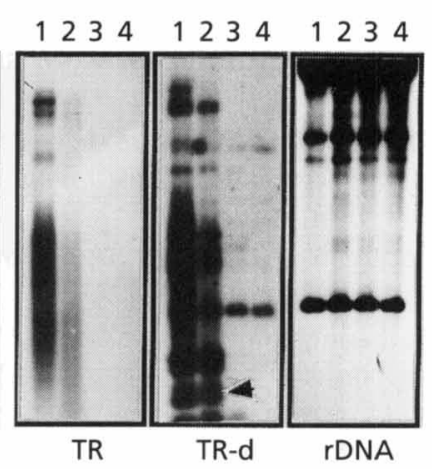

Fig. 4. Bal31 exonuclease sensitivity of Pstl fragments identified by TR and TR-d probes in $U$. maydis strains. DNA from strains (a) FB1, group 1; (b) 13, group 2; (c) P2, group 3 and (d) T4, group 4 was digested for 0 (lane 1), 10 (lane 2), 30 (lane 3) and 60 (lane 4) min with Ba/31, then digested with Pstl, size-fractionated by agarose gel electrophoresis $(0.8 \%$ gel, $1.2 \mathrm{~V} \mathrm{~cm}^{-1}$ for $15 \mathrm{~h}$ ) and transferred to a nylon membrane. Blots were first probed with TR, followed by sequential rehybridization with TR-d and then with $U$. maydis ribosomal DNA (P. Sánchez-Alonso \& P. Guzmán, unpublished). Size standards as in fig. 2.

which are Bal31-sensitive and Bal31-insensitive is established.

DNA from one strain from each of the groups was digested for progressively increasing lengths of time with the exonuclease Bal31 followed by digestion with PstI. Samples were separated by electrophoresis on agarose gels, transferred to membranes and hybridized sequentially to TR, TR-d and U. maydis ribosomal DNA probes (Fig. 4). TR revealed smears which disappeared within 10 min in strains from groups 2 and 3 (Fig. 4b, c, left-hand panels) and after $30 \mathrm{~min}$ in strains from groups 1 and 4 (Fig. 4a, d, left-hand panels). These results indicate that the TR sequence TTAGGG was present at the chromosome termini in these four strains. Analysis of the hybridization with TR-d (Fig. 4a-d, central panels) showed that the proportion of hybridizing fragments varies from one strain to another and that these TAS are present both at chromosome termini and at interstitial sites. The strain from group 1 showed at least six fragments which were present after $60 \mathrm{~min}$ of exonuclease treatment (Fig. 4a, central panel); strains from groups 3 and 4 showed about two Ba/31-insensitive fragments (Fig. $4 \mathrm{c}, \mathrm{d}$, central panels) and strain from group 2 did not show Bal31-insensitive fragments after $60 \mathrm{~min}$ incubation (Fig. $4 \mathrm{~b}$, central panel). The non-telomeric repeated probe revealed a very similar pattern of hybridization during Bal31 treatments in all four groups (Fig. 4a-d, right-hand panels).

This analysis of Bal31 sensitivity indicated that the polymorphisms inferred in Fig. 3 occurred at chromosome termini and at interstitial sites. A distinctive fragment from group 1 was $B a / 31$ insensitive (compare Fig. 3, lanes 1 and 2 with Fig. 4a, middle panel), indicating that it could be located at an interstitial site, whereas fragments from groups 3 and 4 were sensitive to the exonuclease, implying that they may be located at the chromosome termini (compare Fig. 3, lanes 7 and 8 with Fig. 4c, middle panel; Fig. 3, lanes 9-12 with Fig. 4d, middle panel).

\section{Conclusions}

Probes from the telomeric region of the chromosomes yielded highly polymorphic fingerprint patterns in 13 strains of $U$. maydis. With the genetic dissection of the telomeric region performed in this work distinctive fingerprint patterns for each group of strains were observed; polymorphism was detected within TAS and interstitial sites of the chromosome. The main differences were in the pattern of EFs, the presence of amplified bands among the EAFs and the presence or absence of distinct bands.

The approach devised to assess genetic variation tested in this work is suitable for studying the population genetics of $U$. maydis and may be a good general scheme for other fungal systems.

\section{ACKNOWLEDGEMENTS}

We thank Flora Banuett for strains, Fidel Guevara-Lara for helping with DNA preparations and Gabriela Olmedo for discussion and comments on the manuscript. P.S. and M. E.V. acknowledge scholarships from CONACyT and from the Cuauhtémoc Program between Costa Rica and Mexico, respectively. This work was supported in part by the Consejo Nacional de Ciencia y Tecnología (CONACy'T) México.

\section{REFERENCES}

Banuett, F. (1992). Ustilago maydis, the delightful blight. Trends Genet 8, 174-180.

Banuett, F. \& Herskowitz, I. (1989). Different a alleles of Ustilago maydis are necessary for maintenance of filamentous growth but not for meiosis. Proc Natl Acad Sci US A 86, 5878-5882.

Blackburn, E. H. (1994). Telomeres: no end in sight. Cell 77, 621-623.

Bölker, M., Böhner, H. U., Braun, K. H., Görl, J. \& Kahmann, R. (1995). 'Tagging pathogenicity genes in Ustilago maydis by restriction enzyme-mediated integration (REMI). Mol Gen Genet 248, 547--552.

Brown, W. R. A., MacKinnon, P. J., Villasante, A., Spurr, N., 
Buckle, V. J. \& Dobson, M. J. (1990). Structure and polymorphism of human telomere-associated DNA. Cell 63, 119-132.

Church, G. M. \& Gilbert, W. G. (1984). Genomic sequencing. Proc Natl Acad Sci USA 81, 1991-1995.

Farman, M. L. \& Leong, S. A. (1995). Genetic and physical mapping of telomeres in the rice blast fungus, Magnaporthe grisea. Genetics 140 , 479-492.

Foote, S.J. \& Kemp, D. J. (1989). Chromosomes of malaria parasites. Trends Genet 5, 337-342.

Fotheringham, S. \& Holloman, W. K. (1989). Cloning and disruption of Ustilago maydis genes. Mol Cell Biol 9, 4052-4055.

Gold, S. E., Bakkeren, G., Davies, J. E. \& Kronstad, J. W. (1994). Three selectable markers for transformation of Ustilago maydis. Gene 142, 225-230.

Guzmán, P. \& Sánchez, G. (1994). Characterization of telomeric regions from Ustilago maydis. Microbiology 140, 551-557.

Harley, C. B., Futcher, A. B. \& Greider, C. W. (1990). Telomeres shorten during ageing of human fibroblasts. Nature 345, 458-460.

Kamper, J., Reichmann, M., Romeis, T., Bölker, M. \& Kahmann, R. (1995). Multiallelic recognition: nonself-dependent dimerization of the $\mathrm{bE}$ and bW homeodomain proteins in Ustilago maydis. Cell 81, 73-83.

Levis, R. W., Genesan, R., Houtchers, K., Tolar, L. A. \& Sheen, F.M. (1993). Transposons in place of telomeric repeats at a Drosophila telomere. Cell 75, 1083-1093.

Louis, E. J., Naumova, E. S., Lee, A., Naumov, G. \& Haber, J. E. (1994). The chromosome end in yeast: its mosaic nature and influence on recombination dynamics. Genetics 136, 789-802.

Pope, D. D. \& McCarter, S. M. (1992). Evaluation of inoculation methods for inducing common smut on corn ears. Phytopatbology 82 , 950-955.
Richards, E. J. \& Ausubel, F. M. (1988). Isolation of a higher eukaryotic telomere from Arabidopsis thaliana. Cell 53, 127-136.

Sambrook, J., Fritsch, E. F. \& Maniatis, T. (1989). Molecular Cloning: a Laboratory Manual, 2nd edn. Cold Spring Harbor, NY: Cold Spring Harbor Laboratory.

Silhavy, T. J., Berman, M. L. \& Enquist, L. W. (1984). Experiments with Gene Fusions. Cold Spring Harbor, NY: Cold Spring Harbor Laboratory.

Spellig, T., Regenfelder, E., Reichmann, M., Schauwecker, F., Bohlmann, R., Urban, M., Bölker, M., Kamper, J. \& Kahmann, R. (1994). Control of mating and development in Ustilago maydis. Antonie Leewwenhoek 65, 191-197.

Thakur, R. P., Leonard, K. J. \& Pataky, J. K. (1989). Smut gall development in adult corn plants inoculated with Ustilago maydis. Plant Dis 73, 921-925.

Valverde, M. E. (1992). Estudios sobre la infección de Ustilago maydis (buitlacache) y sus caracteristicas alimentarias. Master thesis, CINVESTAV-Irapuato, GTO, Mexico.

Valverde, M. E., Paredes-López, O., Pataky, J. K. \& Guevara-Lara, F. (1995). Huitlacoche (Ustilago maydis) as a food source - biology, composition and production. Crit Rev Food Sci Nutr 35, 191-229.

Wang, J., Holden, D. W. \& Leong, S. A. (1988). Gene transfer system for the phytopathogenic fungus Ustilago maydis. Proc Natl Acad Sci USA 85, 865-869.

Zakian, V. A. (1989). Structure and function of telomeres. Annu Rev Genet 23, 579-604.

Received 19 December 1995; revised 16 April 1996; accepted 6 June 1996. 